\title{
Balantidium coli in Pigs Regularly Slaughtered at Abattoirs of the Province of Messina: Hygienic Observations
}

\author{
Filippo Giarratana, Daniele Muscolino, Gianluca Taviano, Graziella Ziino \\ Department of Veterinary Public Health, Section of Inspection of Food of Animal Origin, Faculty of \\ Veterinary Medicine, University of Messina, Messina, Italy \\ Email: fgiarratana@unime.it
}

Received January 30, 2012; revised February 17, 2012; accepted March 15, 2012

\begin{abstract}
Balantidium coli is a zoonotic protozoan parasite, and pork is considered the major source of Balantidium infection in humans. Transmission is direct and commonly occurs through the ingestion of water and food, especially vegetables, contaminated with infectious cysts. Ingestion of meat contaminated, with faecal material during the evisceration process, can represent a potential risk of $B$. coli transmission. In order to determine the rate of $B$. coli infection in pigs regularly slaughtered at abattoirs in the province of Messina (Sicily, Italy), faecal samples of 242 pigs (122 commercial hybrid and 120 Nero Siciliano pigs) were collected and evaluated by standard methods for the presence of trophozoites and/or cysts. A total of 105 of the commercial hybrid (86.06\%), but only 44 of the Nero Siciliano (36.66\%) pigs, were identified as positive for $B$. coli infection. The results obtained, may be linked to the type of farming employed.
\end{abstract}

Keywords: Foodborn Pathogens; Balantidium coli; Nero Siciliano Pigs; Commercial Hybrid

\section{Introduction}

Balantidium coli is a ciliate intestinal protozoan with a wide host range in vertebrates, e.g. pigs, cattle, chimpanzees, and more rarely, dogs, cats, sheep, horses, and camels [1-6]. There are 2 stages in the life cycle of the protozoan: an infectious cyst stage and a vegetative trophozoite stage. The trophozoite, covered with somatic cilia, measures $30-150 \mu \mathrm{m}$ in length by $25-120 \mu \mathrm{m}$ in width. The cysts, which are spherical or slightly ovoid, measure 40 - $60 \mu \mathrm{m}$ in diameter [7].

Balantidiosis, the disease caused by $B$. coli infection, has been reported in developing countries such as Brazil, Venezuela, the Philippines, Papua New Guinea, and Iran, and in central Asia and certain Pacific Islands [8]. Transmission is direct and commonly occurs through the ingestion of water and food, especially vegetables, contaminated with infectious cysts. Human-to-human transmission may also occur. B. coli infects the caecum and colon in man, and the infections may either remain asymptomatic or, in invasive cases, trophozoites may invade the intestinal epithelium, producing hemorrhagic lesions, ulcerations, abscess formation, or a local generalized peritonitis with perforations [6]. The major factors contributing to the spread of the disease to humans are the presence of infected animals, subtropical and/or tropical climatic conditions, suboptimal hygienic standards, malnutrition, concomitant parasitic infections and debilitating diseases [8,9]. Some cases of $B$. coli infection in immunocompromised patients, including HIV/AIDS patients, patients with malignancies, and transplantation recipients have been reported [10-13].

Pigs, in which species the infection is often asymptomatic, are considered to be the most important animal reservoir for human infection [8]. In fact, although human Balantidiosis is considered to be uncommon, its incidence is higher in communities that live in close association with pigs. In Papua New Guinea, for example, where pigs are the most frequent domestic animals, the infection rates among pig farmers and slaughterhouse workers are as high as $28 \%$ [8].

The evolution of farming towards alternative techniques of breeding (outdoor system, "en plein-air" farming, etc.), the rediscovery of rustic breeds and the European approach to food safety issues, which requires the knowledge of the distribution and prevalence of each hazard along the supply chain, has motivated us to carry out an assessment of the incidence of Balantidiosis in reared pigs in Sicily. The aim of the present study is to evaluate the infection rate of $B$. coli in commercial hybrid (commonly used for meat product industry), and in Nero Siciliano pigs regularly slaughtered at abattoirs of the province of Messina. In particular, no data are available for the Nero Siciliano breed of pigs, which is a special heritage breed whose meat is much prized in traditional Sicilian gastronomy. 


\section{Materials and Methods}

The study was carried out on 242 pigs (122 commercial hybrid and 120 Nero Siciliano pigs) that had been slaughtered at abattoirs of the province of Messina (Sicily, Italy) from March 2009 to June 2010. Information was collected about the animals and farms where they had been raised. In particular, data collection included the following parameters: farm type, sex and age of animals, diet (commercial vs. produced on-farm, or mixed). At the slaughterhouse, the terminal part of the rectum of each pig was withdrawn after evisceration, and it was maintained at $37^{\circ} \mathrm{C}$ and immediately transported to our laboratory for analysis. A method for detecting trophozoites in faeces was developed, in which a suspension of faecal material in $0.9 \%(\mathrm{w} / \mathrm{v}) \mathrm{NaCl}$ was spread on a slide and then examined by light microscopy. Instead, an aliquot of each faecal sample $(5 \mathrm{~g})$ was processed by the flotation method using saturated $\mathrm{NaCl}$, following the method described by Wade and Gaafar [14] to confirm the presence of protozoa. Each observed cyst was identified by using their morphological characteristics. A pig was classified as positive if at least one cyst or trophozoite was found.

\section{Results}

One hundred twenty-two commercial hybrid animals (Petrain $\times$ Large White) were obtained from 4 farms. These pigs were reared under the same intensive farming conditions in bare concrete pens, and they were fed with a commercial diet. The animals (74 male and 48 female) were slaughtered at the age of about 8 months, and at approximately 90 - $120 \mathrm{~kg}$ live weight. The animals sampled, showed often a high faecal skin "contamination". Of the 122 animals studied, 105 (86.06\%) (62 male and 43 female) (Table 1) were tested positive for B. coli infection.

One hundred twenty Nero Siciliano pigs came from 8 "en plein air" farms, located in the mountainous areas of Nebrodi, and they fed on natural plant products (roots, tubers, acorns, wild fruits, etc.; diet varied depending on the season). The breed is a rustic animal, with good adaptability to often unfavourable environmental conditions. The animals (65 male and 55 female) were slaughtered at the age of 6 - 12 months, and at 60 - $120 \mathrm{~kg}$ live weight. No evident faecal skin "contamination" was observed. Of these total 120 animals, 44 pigs (36.66\%; 28 male and 16 female) (Table 2) were found to be infected with B. coli.

Table 1. Incidence of $B$. coli in commercial hybrid pigs.

\begin{tabular}{cccc}
\hline & Pigs sampled & Pigs positive for B. coli & Positive \% \\
\hline Male & 74 & 62 & 83.78 \\
Female & 48 & 43 & 89.58 \\
Total & 122 & 105 & 86.06 \\
\hline
\end{tabular}

Table 2. Incidence of $B$. coli in Nero Siciliano pigs.

\begin{tabular}{cccc}
\hline & Pigs sampled & Pigs positive for B. coli & Positive \% \\
\hline Male & 65 & 28 & 43.07 \\
Female & 55 & 16 & 29.09 \\
Total & 120 & 44 & 36.66 \\
\hline
\end{tabular}

\section{Discussion}

The results we obtained in the present study show a relatively high B. coli infection rate (86.06\%) in commercial hybrid pigs, slaughtered at abattoirs of the province of Messina. Balantidiosis in Nero Siciliano pigs was signifycantly lower (36.66\%). The high infection rate in commercial hybrid breed are consistent with some previous studies that also reported relatively high incidence of $B$. coli in Italy, such as data of De Carneri [15] from Milan (94.8\%), and Nardi [16] from Foggia (100\%). Slightly lower incidence has been reported from Messina (78\%) [17] and from Pisa (68\%) [18].

In other European countries, there are reports of a high prevalence (86\%) in pigs from Iceland [19], as well as from Denmark (varies from 57\% to 100\%) [20]. In contrast, a microscopic investigation of pig faeces from Sardinia (Italy) show a much lower prevalence (15.5\%) of Balantidium coli [21]. In China, Weng et al. [22], show an infection rate of $47.2 \%$ in pigs from intensive farms in Guangdong Province, and more recently a lower prevalence of B. coli was found (22.12\%) in Chongqing [23].

The relatively high parasitic infection rate found in the commercial hybrid breed is probably closely linked to an inadequate management farm system under which the animals were reared. In fact the faecal skin "contamination" observed, indicates probably a high faecal contamination in the farming environment. A study of pigs raised in traditional systems (both indoor and outdoor systems) in China reported infection rates of $90 \%$ for $B$. coli, but much lower rates $(2.1 \%)$ in pigs from modern intensive farms linked to better management and treatment standards [23]. Thus, a correct hygiene management system, based on appropriate knowledge of the epidemiological conditions of the parasitic infection, would be necessary to reduce the prevalence of Balantidium infections.

The lower parasitic infection rate found in the Nero Siciliano pigs is probably related to the techniques of breeding ("en plein air"), different diet, and hardiness of the breed. Furthermore, we believe that the farming system could play a key role in reducing the prevalence of infection with a "dilution" effect on protozoa excreted in the faeces.

Balantidiosis must also be regarded as a risk factor of major concern for hygiene and safety during meat production. The protozoan's transmission from faeces to meat is poorly understood. At the slaughterhouse, meat 
contamination could occur during the evisceration process, as demonstrated by the finding of $B$. coli cysts on scrapings of meat surfaces [24]. Furthermore, there is a certain probability of cross contamination between carcasses. Cystic contamination must be feared because the $B$. coli cyst is the transmissive stage of the organism in human infection. In this regard, however, the trophozoite has also been reported to be infectious in man [7]. Experimental studies have shown that trophozoites may survive on the surface of meat for several hours [24]. According to the latter study, trophozoites that manage to penetrate into the thickness of the muscles would probably remain viable for even longer periods.

The risk factors from the slaughterhouse can lead to the occurrence of $B$. coli in raw meat. In cases of ingestion of raw or improperly cooked pork products, $B$. coli can represent a potential risk for the health of consumers. Indeed, fresh raw sausages can be a source of infection in humans [25]. Furthermore, natural casings, if not well cleaned, may carry the parasite. In contrast to uncooked meat, the risk of cooked meat products is considered to be negligible. The prevention of faecal contamination of the carcasses with digestive tract contents and of smearing of faecal material are important aspects of sanitary slaughter. Particular attention must be paid during evisceration in order to avoid cross-contamination, according to EC Regulation 853/2004. Moreover, food business operators must maintain and retain records relating to measures applied to control hazards, including the occurrence of diseases (such as Balantidiosis) that may affect the safety of products of animal origin, according to EC Regulation 852/2004. Although these measures are specifically aimed to prevent the risk of bacterial infection, they also ensure prevention against parasitic protozoans, such as $B$. coli.

The major risk factor for humans is direct contact with pig faeces; therefore, farmers, abattoir workers, veterinarians, and veterinary students are at risk for contracting Balantidiosis via this route. Normal personal hygienic precautions and a better knowledge of these protozoa can help to limit the spread of parasites.

\section{REFERENCES}

[1] B. H. Ali and M. Abdelaziz, "Balantidiasis in a Camel," Veterinary Record, Vol. 110, No. 21, 1982, p. 506. doi:10.1136/vr.110.21.506

[2] H. O. Cho, S. S. Shin and N. M. Park, "Balantidiasis in the Gastric Lymph Nodes of Barbary Sheep (Ammotragus lervia): An Incidental Finding," Journal of Veterinary Science, Vol. 7, No. 2, 2006, pp. 207-209. doi:10.4142/jvs.2006.7.2.207

[3] H. F. Dewes, "An Occurence of Balantidium coli in Calves,” New Zealand Veterinary Journal, Vol. 7, No. 2, 1959, p. 42. doi:10.1080/00480169.1959.33325

[4] S. A. Headley, E. Kummala and A. Sukura, "Balantidium coli-Infection in a Finnish Horse," Veterinary Parasitology, Vol. 158, No. 1-2, 2008, pp. 129-132. doi:10.1016/j.vetpar.2008.08.013

[5] K. Nakauchi, "The Prevalence of Balantidium coli Infection in Fifty-Six Mammalian Species," Journal of Veterinary Medicine Science, Vol. 61, No. 1, 1999, pp. 63-65. doi:10.1292/jvms.61.63

[6] F. L. Schuster and L. Ramirez-Avila, "Current World Status of Balantidium coli," Clinical Microbiology Reviews, Vol. 21, No. 4, 2008, pp. 626-638.

doi:10.1128/CMR.00021-08

[7] N. D. Levine, "Protozoan Parasites of Domestic Animals and of Man,” Burgess Publishing Co., Minneapolis, 1961.

[8] S. Solaymani-Mohammadi and W. A. Petri Jr., "Zoonotic Implications of the Swine-Transmitted Protozoal Infections," Veterinary Parasitology, Vol. 140, No. 3-4, 2006, pp. 189-203. doi:10.1016/j.vetpar.2006.05.012

[9] A. Giacometti, O. Cirioni, M. Balducci, D. Drenaggi, M. Quarta, M. De Federicis, P. Ruggeri, D. Colapinto, G. Ripani and G. Scalize, "Epidemiologic Features of Intestinal Parasitic Infections in Italian Mental Institutions," European Journal of Epidemiology, Vol. 13, No. 7, 1997, pp. 825-830. doi:10.1023/A:1007306630301

[10] J. R. Cermeno, I. Hernandez de Cuesta, O. Uzcategui, J. Paez, M. Rivera and N. Baliachi, "Balantidium coli in a HIV-Infected Patient with Chronic Diarrhea,” AIDS, Vol. 17, No. 6, 2003, pp. 941-942. doi:10.1097/00002030-200304110-00030

[11] E. Clyti, C. Aznar, P. Coopie, M. el Gueedj, B. Carme and R. Pradinaud, "A Case of Coinfection by Balantidium coli and HIV in French Guiana,” Bulletin de la Société de Pathologie Exotique, Vol. 91, No. 4, 1998, pp. 309-311.

[12] A. Maino, G. Garigali, R. Grande, P. Messa and G. B. Fogazzi, "Urinary Balantidiasis: Diagnostic at a Glance by Urine Sediment Examination,” Journal of Nephrology, Vol. 23, 2010, pp. 732-737.

[13] S. Yazar, F. Altuntas, I. Sahin and M. Atambey, "Dysentery Caused by Balantidium coli in a Patient with Non-Hodgkin's Lymphoma from Turkey,” World Journal of Gastroenterology, Vol. 10, 2004, pp. 458-459.

[14] W. F. Wade and S. M. Gaafar, "Common Laboratory Procedures for Diagnosing Parasitism,” In: J. Colville, Ed., Diagnostic Parasitology for Veterinary Technicians, American Veterinary Publications Inc., St. Louis, 1991, pp. 7-50.

[15] I. De Carneri, "Nuove Osservazioni su Balantidium coli. Diffusione tra i Suini a Milano, Coltivazione, Sensibilità ai Farmaci in Vitro," Rivista Parassitologia, Vol. 20, 1959, pp. 9-28.

[16] E. Nardi, "La Balantidiosi nei Suini e nei Bovini del Comune di Foggia,” Veterinaria Italiana, Vol. 11, 1960, pp. 868-873.

[17] L. Iannuzzi, "Indagini sulla Frequenza di Balantidium coli (Malmsten, 1857) Negli Animali da Macello,” Annali della Facoltà di Medicina Veterinaria di Messina, Vol. 4, 1967, pp. 65-67. 
[18] V. Favati, "Sulla Balantidiosi Suina in Toscana,” Annali della Facoltà di Medicina Veterinaria di Pisa, Vol. 12, 1959, pp. 363-365.

[19] M. M. Eydal and K. Kontisson, "The Prevalence of Balantidium coli and Other Zoonotic Parasites in Icelandic Pigs,” Parasitology International, Vol. 47, Suppl. 1, 1998, p. 313. doi:10.1016/S1383-5769(98)80906-9

[20] O. Hindsbo, C. V. Nielsen, J. Andressen, A. L. Willingham, M. Bendixen, M. Nielsen and N. O. Nielsen, "AgeDependent Occurrence of the Intestinal Ciliate Balantidium coli in Pigs at a Danish Research Farm,” Acta Veterinaria Scandinavica, Vol. 41, No. 1, 2000, pp. 79-83.

[21] L. Polinas, G. Cocco, B. Tanda, M. Basciu, G. N. Sanna Coccone, R. Marrosu, A. P. Pipia, M. S. Nieddu, G. Garippa and A. Scala, "Gastro-Intestinal Parasites of Pigs in Sardinia: A Copromicroscopical Investigation,” Parassitologia, Vol. 28, 2006, p. 313.
[22] Y. B. Weng, Y. J. Hu, Y. Li, B. S. Li, R. Q. Lin, D. H. Xie, R. B. Gasser and X. Q. Zhu, "Survey of Intestinal Parasites in Pigs from Intensive Farms in Guangdong Province, People's Republic of China," Veterinary Parasitology, Vol. 127, No. 3-4, 2005, pp. 333-336. doi:10.1016/j.vetpar.2004.09.030

[23] M. Lai, R. Q. Zhou, H. C. Huang and S. J. Hu, "Prevalence and Risk Factors Associated with Intestinal Parasites in Pigs in Chongqing, China," Research Veterinary Science, Vol. 91, No. 3, 2011, pp. 121-124. doi:10.1016/j.rvsc.2011.01.025

[24] F. Panebianco, "Igiene delle Carni e Balantidium coli (Malmsten, 1857),” Annali della Facoltà di Medicina Veterinaria di Messina, Vol. 4, 1967, pp. 49-64.

[25] E. J. A. Brumpt, "Precis de Parasitology," 6th Edition, Masson CE, Paris, 1949. 